\title{
DIREITOS FUNDAMENTAIS E DEVER JURÍDICO: ESTADO, INDIVÍDUO E COLETIVIDADES
}

CARLA TORQUATO

Doutoranda pelo Programa de Pós-Graduação em Direito pela FADISP - Faculdade Autônoma de São Paulo. Possui graduação em Direito pela Universidade Federal Fluminense (1995) e mestrado em Direito Ambiental pela Universidade do Estado do Amazonas (2008). É pesquisadora do CNPq no grupo de pesquisa GEDA - Grupo de Estudos em Direito de Águas, da Universidade do Estado do Amazonas e também associada ao CONPEDI - Conselho Nacional de Pesquisa e PósGraduação em Direito e a Waterlat-Gobacit - Rede internacional de pesquisas sobre água.

\section{JOSSIANI DIAS}

Doutoranda pelo Programa de Pós-Graduação em Direito pela FADISP - Faculdade Autônoma de São Paulo.Mestre em Ciências Jurídicas com ênfase em Direitos da Personalidade pelo Centro Universitário de Maringá (2017). Pós-Graduada em Direito Público Material, pela Universidade Gama Filho-Rj. Pós-Graduada em Direito Aplicado Lato Sensu, pela Escola da Magistratura do Paraná, (2008). Membro do Órgão Colegiado da Faculdade Santa Maria da Glória. Atualmente é Professora de Direito Constitucional da Faculdade Santa Maria da Glória de Maringá-PR. Advogada.

\section{INTRODUÇÃO}

Considerando o atual estágio de desenvolvimento da sociedade brasileira, bem como o pluralismo característico de sua ordem jurídica, o presente estudo aborda um tema de suma importância para um estado democrático de Direito: Os 


\section{Personalidade Acadêmica Homenageada:}

Florisbal de Souza Del'Olmo (Professor Convidado - UNICURITIBA)

Direitos fundamentais e direitos humanos. Qual a diferença entre ambos? Qual a efetividade desses direitos no ordenamento jurídico? Todos são titulares dos direitos fundamentais?

Notável a importância de compreender, como o direito regula a sociedade, as relações interpessoais e os comportamentos do sujeito contemporâneo. O objetivo geral deste trabalho, é analisar a efetividade e aplicação dos direitos humanos e fundamentais, demonstrando a importância da liberdade, afetividade, solidariedade e Dignidade da Pessoa Humana, para instituir um direito que agrega e protege as transformações de ordem moral, ética e cultural, sendo que o dever do Estado é gerenciar essas questões individuais e coletivas, efetivar os direitos fundamentais cuidando para não ferir a autonomia da vontade. Consigna-se, para o desenvolvimento deste trabalho, utilizou-se os métodos históricos, em busca de se compreender o contexto atual vivenciado, além do método indutivo, buscando alcançar soluções que corrobore para efetivação dos direitos fundamentais.

PALAVRAS- CHAVE: Direitos Fundamentais; Dever Jurídico; Estado; Indivíduo.

\section{DOS DIREITOS HUMANOS E FUNDAMENTAIS}

Atualmente, a valorização da pessoa humana bem como o reconhecimento de que todo ser humano é dotado de dignidade, outorga a pessoa humana um valor que não decorre de raça, cor, sexo, cultura, religião ou das experiências de vida, mais sim de um valor intrínseco do indivíduo que merece ser respeitado como o principal destinatário da ordem jurídica.

Diante da atual perspectiva, que coloca o ser humano no centro do ordenamento jurídico, uma das principais causas do Estado Democrático de Direito está ligada a garantia aos bens jurídicos fundamentais, evidenciando os Direitos Humanos, intentando a proteção dos direitos mínimos e básicos como a vida, a saúde e a liberdade das pessoas. 


\section{Personalidade Acadêmica Homenageada:}

Florisbal de Souza Del'Olmo (Professor Convidado - UNICURITIBA)

A vista disso, é preponderante destacar, que apesar de serem frequentemente utilizadas como expressões sinônimas, em termos históricos podemos dizer que os direitos humanos antecedem os direitos fundamentais, se confundindo com os direitos naturais, as leis não escritas, de cunho divino, cujas raízes são a dignidade humana, a fraternidade, a igualdade e a liberdade.

Nessa vertente, os Direitos humanos são atemporais, universais e possuem caráter inviolável, são inerentes ao indivíduo e anteriores a qualquer contrato social. Já os direitos fundamentais, mesmo carregando o peso dos princípios atinentes aos direitos humanos, possuem caráter normativo, ou seja, leis feitas pelos humanos que tratam daquilo que é mais caro, mais valioso para os demais humanos, tidos como as regras necessárias para uma vida harmônica e coletiva visando sempre proteger a dignidade da pessoa humana, que é não somente utilizada como direito da pessoa, mas também como limite do poder.

As questões do sentido do direito como regulador e protetor da sociedade, sempre esteve presente, emergente do Direito Natural aludimos a teoria hobbesiana, que considerou o direito natural "um conjunto de direitos inatos e invioláveis, inerentes aos indivíduos, de modo que o Estado deveria ser concebido para garantir

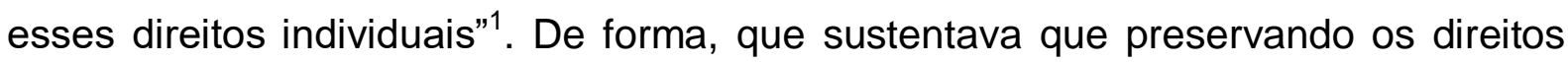
individuais, "o Estado estaria protegendo também a sociedade, conservando o bem comum". Ainda ressalta-se a afirmação de John Locke ${ }^{2}$, "os direitos naturais definem os limites do poder soberano na sociedade civil, "de modo que estado natural e sociedade civil não estariam absolutamente desligados".

Mendes e Branco ${ }^{3}$ estabelecem como traço divisor entre os direitos humanos e os direitos fundamentais o elemento juridificante da positivação. Ele os distingue, de uma forma bem simples, respectivamente, como um sendo as

\footnotetext{
${ }^{1}$ HOBBES, Thomas. Leviatã ou matéria, forma e poder de um estado eclesiástico e civil. Coleção "a obra-prima de cada autor". Tradução de Alex Marins. São Paulo: Martin Claret, 2006, p.27.

2 LOCKE, John. Segundo tratado sobre o governo civil: ensaio sobre a origem, os limites e os fins verdadeiros do governo civil. Introdução de J.W. Gough. Tradução de Magda Lopes e Marisa Lobo da Costa. Petrópolis-RJ: Vozes, 1994, p. 39.

${ }^{3}$ MENDES, Gilmar Ferreira; BRANCO, Paulo Gustavo Gonet. Curso de Direito Constitucional. 8 ed. São Paulo: Saraiva, 2013, p.147.
} 


\section{Personalidade Acadêmica Homenageada:}

Florisbal de Souza Del'Olmo (Professor Convidado - UNICURITIBA)

pretensões de respeito à pessoa humana, inseridas nos tratados e convenções de direito internacional, e o outro como os direitos relacionados as posições básicas das pessoas, inscritos nos diplomas legais de cada Estado, que vigem numa ordem jurídica concreta.

Não entrando aqui na discussão de um tratado estar ou não recepcionado na ordem jurídica pátria, recorro a Bobbio ${ }^{4}$, ao avaliar que os direitos do homem são aqueles cujo reconhecimento é condição necessária para o aperfeiçoamento da pessoa humana. Bobbio, ao fazer uma comparação entre o que são liberdades e poderes, chega no ponto em que desejamos, ao dizer que liberdades são os direitos que são garantidos quando o Estado não intervém e de poderes, os direitos que exigem uma intervenção do Estado para a sua efetivação.

Nesta toada, liberdades e poderes não são incompatíveis, porém, resta evidente que quando estamos perante uma norma positivada temos o poder de exigir, mediante o binômio norma e sanção o seu cumprimento de maneira efetiva.

Para Canotilho ${ }^{5}$, os direitos fundamentais, para que sejam entendidos desta maneira, devem estar positivados na constituição, pois os direitos do homem são esperanças, aspirações, ideias, impulsos ou até, por vezes, mera retórica política, mas não direitos sob a forma de normas, regras e princípios de direito constitucional.

Em termos, segundo Mendes e Branco, presente na Constituição, os direitos fundamentais são parâmetro de organização e de limitação dos poderes Legislativo, Executivo e Judiciário. No âmbito do poder Legislativo, não somente a atividade legiferante deve ser coerente com o sistema de direitos fundamentais, como deve assumir uma postura de criar conteúdo infraconstitucional, que efetive estes direitos.

O poder Executivo, ou seja, a administração, deve interpretar e aplicar as leis segundo os direitos fundamentais, sendo nulos os atos que os ofendem. Já ao Judiciário cabe a tarefa de defender os direitos violados ou ameaçados (art. $5^{\circ}$, XXXV, CF/1988). A defesa dos direitos fundamentais é da essência a sua função.

\footnotetext{
${ }^{4}$ BOBBIO, Norberto. A Era dos Direitos. 14 ed. Rio de Janeiro: Campus, 1992, p.17-43.

${ }^{5}$ CANOTILHO, Joaquim José Gomes. Direito Constitucional. 5 ed. Coimbra: Almedina, 1991, p. 507.
} 


\section{Personalidade Acadêmica Homenageada:}

\section{Florisbal de Souza Del'Olmo (Professor Convidado - UNICURITIBA)}

Os tribunais detêm a prerrogativa de controlar os atos dos demais poderes, com o que definem o conteúdo dos direitos fundamentais elencados pelo constituinte ${ }^{6}$.

\section{OS TITULARES E OS DESTINATÁRIOS DOS DIREITOS FUNDAMENTAIS}

Sob a égide histórico-cultural, subsequentemente a tantos movimentos nacionais e internacionais, evidente um progresso no que diz respeito a proteção da pessoa humana no Estado democrático de Direito. Hodiernamente, tanto as pessoas físicas ou jurídicas, de direito público ou privado, podem ser titulares ou destinatários de direitos fundamentais, mantendo-se assim o respeito que se deve coexistência social.

Nota-se um sistema que pretende unificar alguns direitos inerente ao ser humano consagrando-os e destinando a toda e qualquer pessoa sem qualquer distinção. $O$ art. $5^{\circ}$ da Constituição Federal afirma que todos são iguais perante a lei, sem distinção de qualquer natureza, garantindo-se aos brasileiros e aos estrangeiros residentes no País a inviolabilidade do direito à vida, à liberdade, à igualdade, à segurança e à propriedade.

Neste contexto, segundo Sarlet, Marinoni e Mitidiero $^{7}$ a titularidade diz respeito ao sujeito de direito, isto é, o sujeito ativo da relação de direito subjetivo. Já o destinatário do direito é a pessoa física, jurídica ou ente despersonalizado em face do qual o titular pode exigir o direito, a proteção ou a promoção do seu direito.

Segundo os autores, o princípio da universalidade determina que todas as pessoas, pelo simples fato de serem pessoas, são titulares de direitos e deveres fundamentais, o que não significa não possam haver diferenças, não sendo então incompatível o fato de que, por exemplo, direitos que são atribuídos apenas a terminadas categorias de pessoas, como os consumidores, os apenados ou os trabalhadores.

\footnotetext{
${ }^{6}$ MENDES, Gilmar Ferreira; BRANCO, Paulo Gustavo Gonet. Curso de Direito Constitucional. 8 ed. São Paulo: Saraiva, 2013, p.148-153.

7 SARLET, Ingo; MARINONI, Luiz Guilherme; MITIDIERO, Daniel. Curso de Direito Constitucional. 6 ed. São Paulo: Saraiva, 2017, p. 356-358.
} 
Personalidade Acadêmica Homenageada:

Florisbal de Souza Del'Olmo (Professor Convidado - UNICURITIBA)

\section{CONCLUSÃO}

Os direitos fundamentais e o respeito a eles, constituem-se no núcleo da legislação constitucional e infraconstitucional brasileira e estrangeira. Verifica-se que, destarte o fato da importância dos direitos humanos, eles somente são alçados um grau de legitimidade e vinculação e coercibilidade quando são positivados.

$\mathrm{Na}$ atualidade, existe uma certa invisibilidade na eficácia de garantir proteção a todos, constantemente defrontamos com diferenças desigualizantes na sociedade, porém, a todos cabem ter respeitados seus direitos fundamentais.

Os direitos humanos, as normas constitucionais, os diversos tratados internacionais não garantem de forma eficiente a proteção e o respeito a todos os seres humanos. Ao passo que existe uma extrema necessidade de a ciência jurídica acompanhar o desenvolvimento social e proteger as mais diversas formas de estados pessoais, o direito deve resguardar a ética através de comandos que atendam a todos.

\section{REFERÊNCIAS}

ALEMANHA. LEI FUNDAMENTAL ALEMÃ. Disponível em <https://www.btgbestellservice.de/pdf/80208000.pdf > Acesso em 08. Set 2018.

BOBBIO, Norberto. A Era dos Direitos. 14 ed. Rio de Janeiro: Campus, 1992.

COMPARATO, Fábio Konder. A Afirmação Histórica dos Direitos Humanos.10 ed. São Paulo: Saraiva, 2015.

CANOTILHO, Joaquim José Gomes. Direito Constitucional. 5 ed. Coimbra: Almedina, 1991.

COMITÉ INTERNACIONAL DA CRUZ VERMELHA. Protocolos Adicionais às Convenções de Genebra de 12 de agosto de 1949. Genebra: CICV, 2015. 
Personalidade Acadêmica Homenageada:

Florisbal de Souza Del'Olmo (Professor Convidado - UNICURITIBA)

HESSE, Konrad. Elementos de Direito Constitucional da República Federal da Alemanha. Porto Alegre: Sérgio Fabris Editor, 1998.

KELSEN, Hans. Teoria Geral do Direito e do Estado. 5 ed. São Paulo: Martins Fontes, 2016.

MENDES, Gilmar Ferreira; BRANCO, Paulo Gustavo Gonet. Curso de Direito Constitucional. 8 ed. São Paulo: Saraiva, 2013.

MARTINS NETO, João dos Passos. Direitos fundamentais - Conceito, função e tipos. São Paulo: RT, 2003.

SARLET, Ingo; MARINONI, Luiz Guilherme; MITIDIERO, Daniel. Curso de Direito Constitucional. 6 ed. São Paulo: Saraiva, 2017 